\title{
Correction to: Soil Quality Status in Different Region of Nepal
}

\author{
Anup K C and Ambika Ghimire
}

\section{Correction to: \\ Chapter 6 in: D. G. Panpatte, Y. K. Jhala (eds.), Soil Fertility Management for Sustainable Development, https://doi.org/10.1007/978-981-13-5904-0_6}

The original version of this chapter was inadvertently published without the sources for Tables 6.1, 6.2 and 6.3.

The current version of the chapter had been revised with the following sources added:

Table 6.1 source: Adapted and modified from Khadka et al. (2017)

Table 6.2 source: Adapted and modified from Tripathi and Jones (2010)

Table 6.3 source: Adapted and modified from Tripathi and Jones (2010) 